\title{
Critical Sources of Aerodynamic Resistance in a Medium Distance Urban Train: a CFD approach*
}

Fuentes críticas de resistencia aerodinámica en un tren urbano de mediana distancia: un enfoque CFD

\section{Andrés F. Tabares, Natalia Gómez César Nieto, Mauricio Giraldo}

\section{Abstract}

In this article, the aerodynamic behavior of a commuter train operating at average speeds is evaluated, by means of computational fluid dynamics; the main goal is to identify the main aerodynamic drag sources. The study consist of two phases; the first one is the aerodynamic analysis of the current train using certain mesh parameters and the turbulence model - to obtain a real condition of operation, with this analysis was obtained the total power consumption corresponding to the value of the aerodynamic drag thrown by the simulation process. These results were qualitatively compared with experimental data in order to validate the simulation process. The second part is the identification and analysis of the main aerodynamic drag zones that the Metro system generate in its interaction with the air, to make a preliminary evaluation of a few modifications that allowed the reduction in the drag in these critical zones. Results obtained show the critical zones, the sources of aerodynamic drag that impact negatively on the system and some evidence that there is a potential reduction in the total drag force influencing energy consumption via some minor aerodynamic changes to the frontal structure, without affecting the operational characteristics of the metro system.

Keywords: aerodynamics, energy consumption, commuter train for urban areas, aerodynamic drag.

\section{Resumen}

El presente artículo evalúa el comportamiento aerodinámico de un tren de cercanías que funciona a velocidades medias, por medio de la dinámica computacional de fluidos. Su objetivo principal es identificar las principales fuentes de resistencia aerodinámica. El estudio consta de dos fases, la

- Fecha de recepción del artículo: 02-12-2012 • Fecha de aceptación: 12-02-2013

ANDRÉS F. TABARES. Aeronautical Engineer and member of the Research Group on Energy and Thermodynamics; Universidad Pontificia Bolivariana. E-mail: andres.tabares@upb.edu.co. NATALIA GÓMEZ VELÁSQUEZ. Mechanical Engineer and member of the Research Group on Energy and Thermodynamic and Research Group of Aerospace Engineering from Universidad Pontificia Bolivariana. E-mail: natalia. gomezv@upb.edu.co. MAURICIO GIRALDO OROZCO. PhD in Thermodynamic and Engineering. Mechanical Engineer. Advanced Training Director. Member of the research group in energy and thermodynamic Universidad Pontificia Bolivariana. E-mail: mauricio.giraldo@upb. edu.co. CESAR NIETO. PhD in Thermodynamics and Engineering, master in Mechanical Engineer. Member of the Research Group on Energy and Thermodynamic and Research Group of Aerospace Engineering, Universidad Pontificia Bolivariana. E-mail: cesar.nieto@upb.edu.co.

* This article of scientific and technological research is derived from the project "Increasing energy efficiency and user comfort in Medellín metro using computational fluid simulation Phase I: Aerodynamic resistance and ventilation", Energy and Thermodynamics research group and Aerospace Engineering Group, Research Line "Simulation and Modeling / Aerodynamics". School of Engineering, School of Mechanical and Aerospace Engineering, supported by Universidad Pontificia Bolivariana and Empresa de Transporte Masivo del Valle de Aburrá Ltda. - Metro de Medellín Ltda Contract: 518-2009 Code: 1210-454-22103 Start Date: January 2010. Due Date: December 2011. 
primera de ellas es el análisis aerodinámico del tren usando ciertos parámetros de malla y el modelo de turbulencia $\mathrm{k}-\varepsilon$ para obtener una condición real de la operación; se obtuvo con este análisis el consumo total de potencia correspondiente al valor de la resistencia aerodinámica lanzada por el proceso de simulación. Estos resultados fueron cualitativamente comparados con los datos experimentales con el fin de validar el proceso de simulación. La segunda parte es la identificación y análisis de las principales zonas de resistencia aerodinámica que el sistema de metro puede generar en su interacción con el aire, para hacer una evaluación preliminar de algunas modificaciones que permitieron la reducción de la resistencia en estas zonas críticas. Los resultados obtenidos muestran las zonas críticas, las fuentes de resistencia aerodinámica que impactan negativamente en el sistema y alguna evidencia de que hay una reducción potencial en la fuerza de arrastre total de influir en el consumo de energía a través de algunos cambios aerodinámicos menores a la estructura frontal, sin afectar a las características operativas del sistema de metro.

Palabras clave: aerodinámica, consumo de energía, tren de cercanías, resistencia aerodinámica.

\section{Introduction}

Reducing aerodynamic drag in commuter trains can be quite important as the velocity increase. It is a task where great improvements are needed, given that most of the urban and suburban fleets were designed more than 30 years ago with little or none consideration of the aerodynamic behavior. However, the aerodynamic analysis is the most difficult part of the design process, since it requires the evaluation of air flow at different speeds and it is often tackled using CAE (Computer Aided Engineering) software, as Computational Fluid Dynamics or CFD.

This approach has been applied in the past with the aim of improving the high speed trains aerodynamic, Baker (2010). In a similar research, Raghunathan et al. (2002) explored a high speed rail road system to design an external geometry as efficient as possible in terms of aerodynamic drag. The railway behavior under cross wind conditions was reported by, Ripamonti et al. (2010) for the new EMUV250 train. In that work, the objective was to obtain an aerodynamic optimization in a critical condition. Baker (2010) also carried out a study of the cross wind forces on trains in order to know the effects on the system.

Wood and Bauer (2003) and Kambiz Salari et al. (2006) studied the aerodynamic of heavy road vehicles, aiming to create designs that could diminish the fuel consumption by reducing the aerodynamic drag

Lienhart et al. (2008) explored the results of the adaptation of surfaces with different roughness and dimples in order to reduce the aerodynamic drag. Ünal and Gören (2011) obtained drag reduction by studying the fluid behavior around a surface with a passive modification, specifically, with the implementation of vortex generators over a circular cylinder surface. The implementation of vortex generators and rotatory surfaces that decrease the flow detachment at the rear zone of bluff bodies was proposed in Ortega et al. (2005) patent, and Beaudoin et al. (2006) study, respectively. The use of vibrating surfaces that avoid the creation of recirculation bubbles through the perturbation of the boundary layer was done by Augustine $e t$ al. (2012).

With this in mind, computer simulations of the aerodynamic behavior of a train belonging to the Empresa de Transporte Masivo del Valle de Aburrá Ltda, also known as Metro de Medellín, were performed using Ansys Fluent 12.1 ${ }^{\circ}$. These simulations allow to calculate the drag distribution on the surfaces composing the train body in order to identify the places where geometric changes could be made to reduce the drag.

\section{Problem description}

In the city of Medellin (Colombia) operates the Empresa de Transporte Masivo del Valle de Aburrá Limitada which operates a train fleet with an external geometry typical of a non-aerodynamic body due to its square form, (see Figure 1). Consequently, the aerodynamic drag generated in its motion produces a strong opposing force that is highly representative in the total power consumption. For this reason the present work evaluates the value of this consumption, leading to identify 
Figure 1

Illustration of the external geometry of the Rail motor

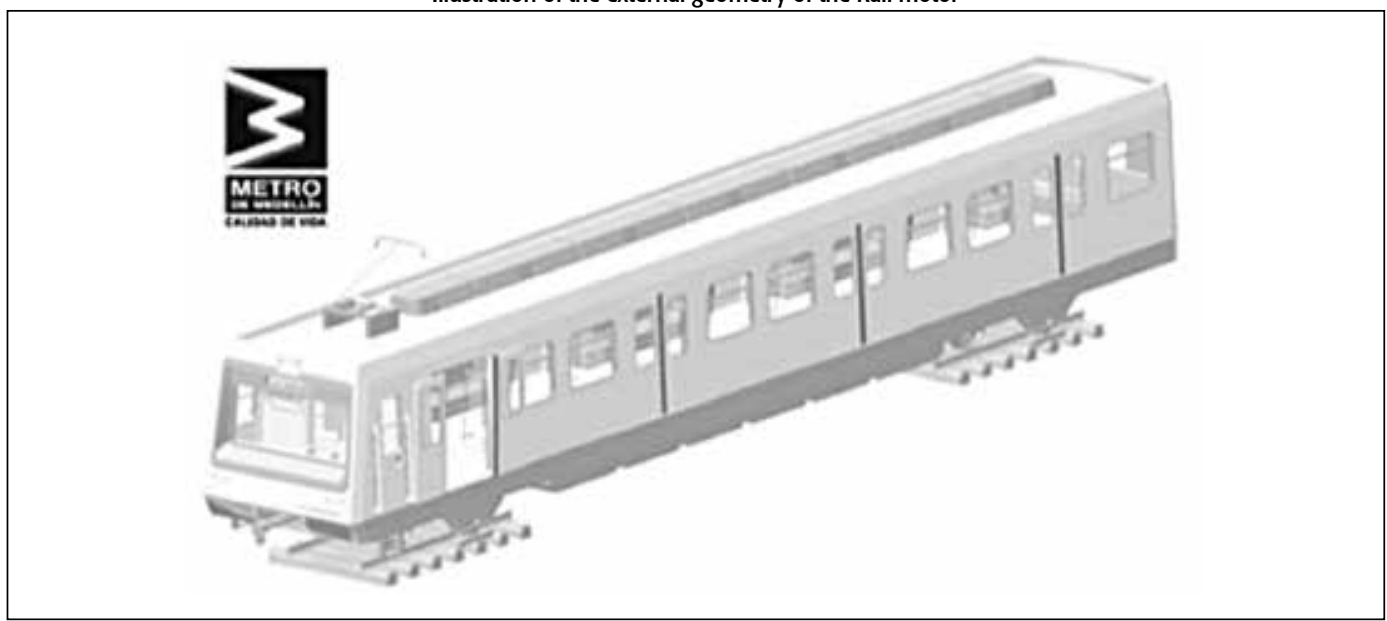

the critical sources of drag and study preliminary modifications that could provide a better aerodynamic behavior, in order to allow a more efficient use of energy and thus economic resources.

\section{Operating conditions}

The current outlay of the train system consists of two lines, named A and B. For simplification effects, the evaluation of drag effects was done only in the route corresponding to the $\mathrm{A}$ line, because this is the longest and fastest track, therefore, the most influential in terms of energy consumption. By dividing the $\mathrm{A}$ line into a middle and external sections (see Figure 2), and using the information from velocity curves, it can be calculated that the trains moves at an average speed of $17.9 \mathrm{~m} / \mathrm{s}$ in the external segments and $13.4 \mathrm{~m} / \mathrm{s}$ in the middle section.

\section{Geometry development and control volume definition}

Starting from the full scale and detailed external model for the train designed in Solid Edge ST2 supplied by the company, a simplified geometrical model was constructed where different surface details were removed to avoid a negative impact in the computational mesh (see Figure 3). Among these simplifications can be found the replacement of sharp angles by small radius curvatures and minor details that were not relevant in the aerody- namic performance, such as junctions in windows and doors, some of the control boxes and details under the train, and some minor elements in the pantograph, which is the mechanical element that maintains physical contact between the train and the power lines.

Given that this paper deals with a problem of external flow, an adequate computational domain must be defined, that assures that the effects generated by the interaction of the air flow with the geometry were not affected by the external boundaries. This was done by calculating the velocity profile at the middle of the domain in order to determine the height at which the calculated velocity reaches that of free air flow $\left(\mathrm{V}_{\infty}\right)$ and possible perturbations which are not evident (see Figure 4). From above the figure it can be concluded that the domain height must be at least 20 meters corresponding to 5 hydraulic diameters. The general dimensions of the control volume are presented in Table 1.

Table 1

General dimensions of the control volume

\begin{tabular}{|c|}
\hline Axis $x(+)=5^{*} b$ \\
\hline Axis $x(-)=9 * b$ \\
\hline Axis $y(+)=4^{*} b$ \\
\hline Axis $y(-)=4^{*} b$ \\
\hline Axis $z(-)=0.025 * b$ \\
\hline
\end{tabular}


Figure 2

Speed zones at Line A

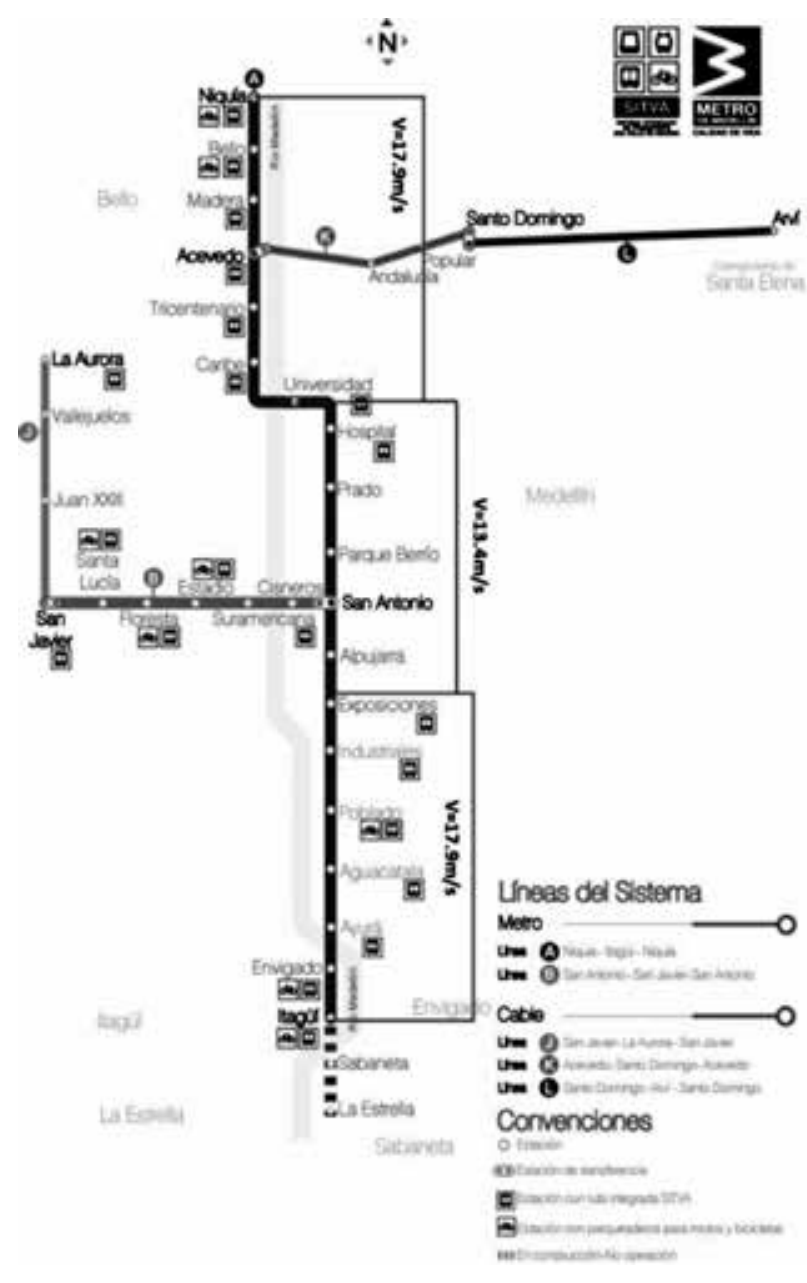

Figure 3

Simplified CAD geometry 
Figure 4

Velocity profile at the center of the domain

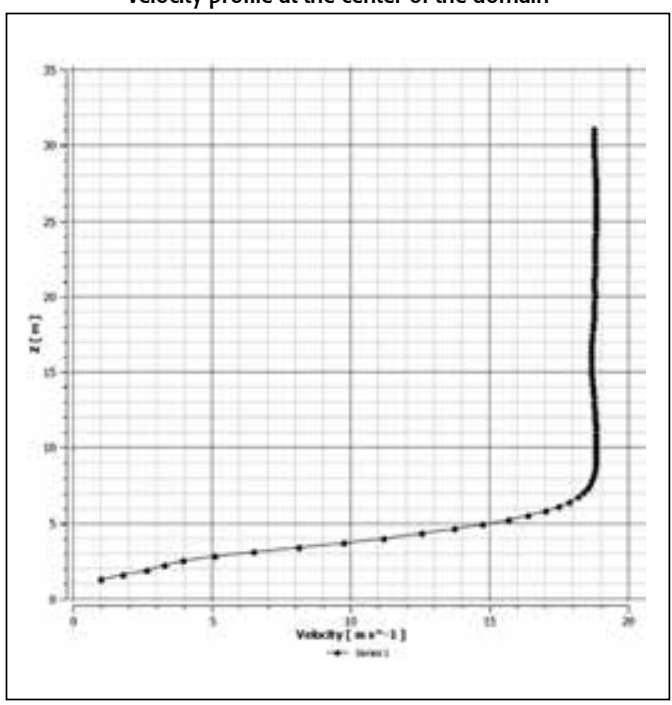

In Table $1, \mathrm{~h}$ equals a value of $4 \mathrm{~m}$ which roughly corresponds to the hydraulic radius of the train. In order to obtain a better control over the computational mesh, the fluid volume was divided into two subdomains, one surrounding the train geometry and its vicinities and the other one corresponds to the outer volume. Alongside these subdomains, two extras geometries were included with the purpose to allow for further mesh refinements at the frontal and rear zones, as illustrated in Figure 5.

\section{Meshing process and boundary conditions}

The generated mesh has 29'725.814 tetrahedral elements with 52'120.622 nodes, divided into the two volumes mentioned in the preceding section, where the volume closer to the geometry has an upper refining grade (see Figure 6) with the objective of solving more accurately the flow gradients generated by the geometry variations.

Finally, two additional subdomains were included which purpose is to influence the generated mesh (see Figure 7) locally refining it even further. These two geometries cover the frontal and rear zone since it is in these zones where the flow field develops the highest gradients: the frontal face is the one which receives the direct impact of the flow and its upstream influence is an important factor; the rear part is the place where the bigger flow
Figure 5

Control Volume

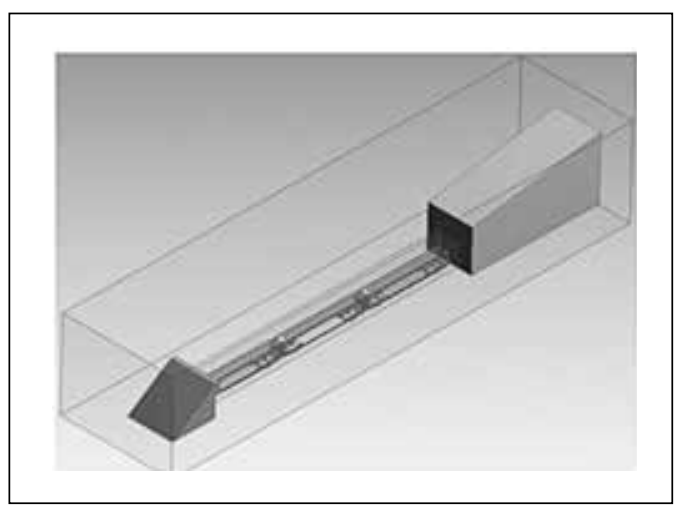

Figure 6

Surface mesh

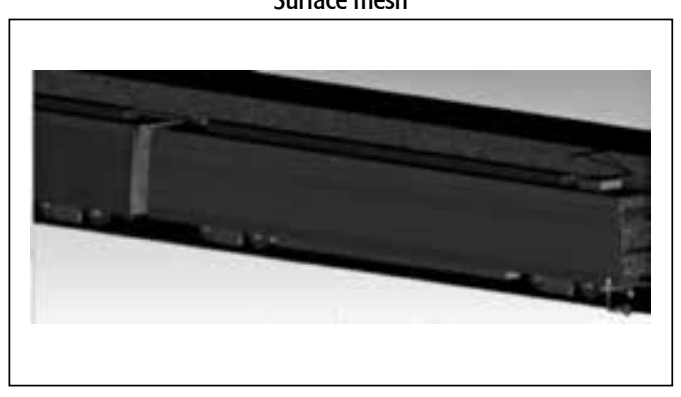

Figure 7

General mesh with body influence

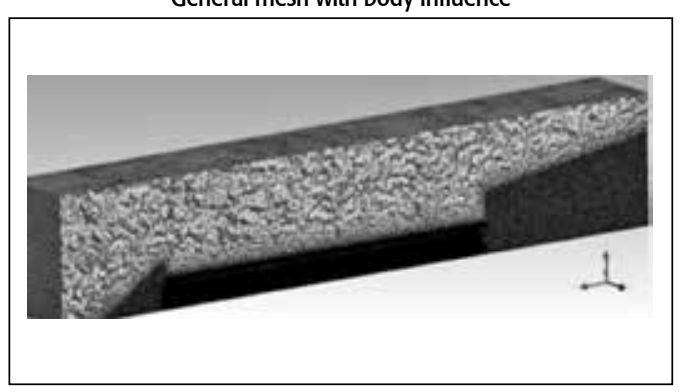

detachment occurs as consequence of the bluff body geometry, which in turn contribute to the generation of the wake, vortex, recirculation and its subsequent effects on the train aerodynamic.

The quality of the resulting mesh is evident in the statistics of it; some of them are shown in Figure 8. From the values presented in this figure it can be stated that the mesh obtained has the correct and necessary parameters to carry out a reliable and accurate simulation. Furthermore, with the refining in the vicinity of the geometry it was intended to ascertain that turbulence quantities found in this complex turbulent flow were properly solved, in that order, it was evaluated a 
geometrical quantity that relates the mesh refinement and the turbulent parameters known as $Y^{*}$, obtaining for this case values between 3 and 300 , as recommended by Ansys Fluent, guaranteeing an appropriate refining along the surface during the solution process shown in Figure 9.

\section{Calculation model}

As it was already mentioned, the simulation process was carried out using Ansys ${ }^{\circledR}$ which offers a CFD tool (Fluent 12.1) that uses a finite volume method to solve the governing fluid equations. The $k-\varepsilon$ turbulence model with standard wall treatment was chosen for the reason that it permits to consider a complete turbulent flow with strong adverse pressure gradients, detachments, recirculation and vortex shedding, where the intermolecular viscous effects are negligible. $k-\varepsilon$ is composed by two transport equation model which allows to independently determine the scale length and the turbulence velocity for a mesh with a $\mathrm{Y}^{*}$ as that obtained for the simulation presented in this paper. Such transport equations constitute a semi-empirical model based on the Turbulence Kinetic Energy (K) and Energy Dissipation Rate (囚) equations.

Equations (1) to (5) present the mathematical model solved in the simulation process.

Continuity:

$$
\frac{\partial u_{i}}{\partial x_{i}}=0
$$

Figure 8

(A) Element quality, (B) Element aspect ratio.

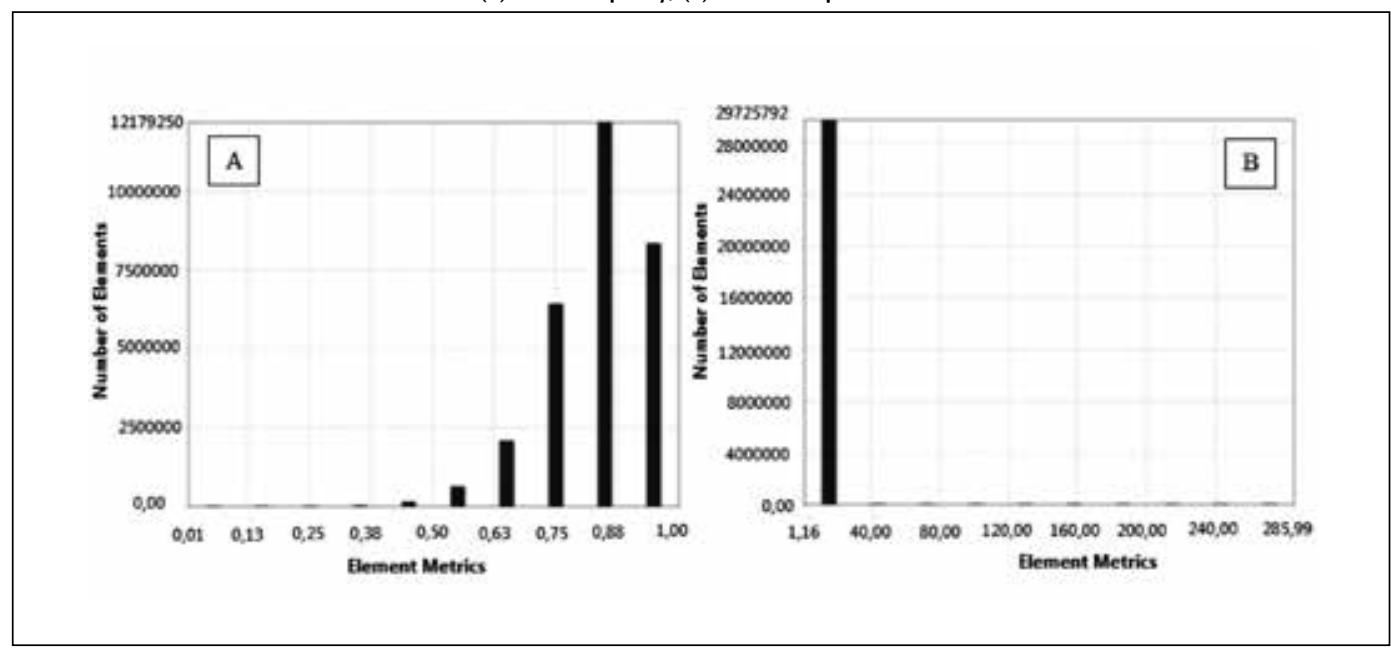

Figure 9

$\mathrm{Y}^{*}$ along the surface

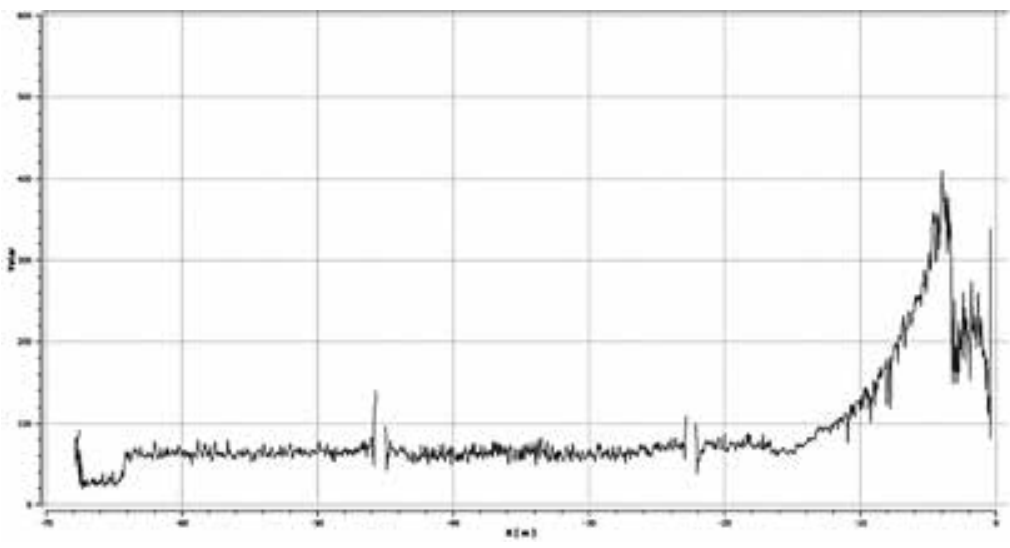

$116<$ Universidad de San Buenaventura, Cali - Colombia 
Momentum:

$\rho\left(\frac{\partial u_{i}}{\partial t}+\frac{\partial\left(u_{i} u_{j}\right)}{\partial x_{j}}\right)=-\frac{\partial P}{\partial x_{i}} \frac{\partial}{\partial x_{j}}\left((\mu+\mu) \frac{\partial u_{i}}{\partial x_{j}}\right)$

where $u, P$ and $\rho$ are the velocity vector, static pressure and density, respectively. For the Eddy Viscosity modeling $\mu_{t}$, are related the Turbulence Kinetic Energy (K) and Energy Dissipation Rate $(\mathbb{\nabla})$ as follows:

$$
\mu_{t}=\rho C_{\mu} \frac{k^{2}}{\varepsilon}
$$

where $C_{\mu}$ is a constant with a common value of 0.09 . For the turbulence model $k-\varepsilon$, the next two equations are solved:

Turbulence Kinetic Energy:

$$
\begin{gathered}
\rho\left(\frac{\partial k}{\partial t}+\frac{\partial\left(u_{i} k\right)}{\partial x_{i}}\right)=\frac{\partial}{\partial x_{i}}\left(\left(\mu+\frac{\mu t}{\sigma_{k}}\right) \frac{\partial k}{\partial x_{i}}\right) \\
+\left(\mu t\left(\frac{\partial u_{i}}{\partial x_{j}}+\frac{\partial u_{j}}{\partial x_{i}}\right)\right) \frac{\partial u_{i}}{\partial x_{j}}-\rho \varepsilon
\end{gathered}
$$

Energy Dissipation Rate:

$$
\begin{aligned}
& \rho\left(\frac{\partial \varepsilon}{\partial t}+\frac{\partial\left(u_{i} \varepsilon\right)}{\partial x_{i}}\right) \\
= & \frac{\partial}{\partial x_{i}}\left(\left(\mu+\frac{\mu t}{\sigma_{\varepsilon}}\right) \frac{\partial \varepsilon}{\partial x_{i}}\right)+C_{\varepsilon^{1}} \frac{\varepsilon}{k}\left(\mu t\left(\frac{\partial u_{i}}{\partial x_{j}}+\frac{\partial u_{j}}{\partial x_{i}}\right)\right) \frac{\partial u_{i}}{\partial x_{j}} \\
- & \rho C_{\varepsilon^{2}} \frac{\varepsilon^{2}}{k}
\end{aligned}
$$

where $C_{\varepsilon 1}$ is a constant equal to $1.44, C_{\varepsilon 2}$ has a value of $1.92, \sigma_{k}$ equals 1.0 and $\sigma_{\varepsilon}$ has a value of 1.3. These constants were previously included into the model and were obtained from experiments with air and water for fundamental turbulent shear flows. For the solution of the above equations an upwind spatial discretization scheme with central cell interpolation values for the convective terms and a central differential scheme with a second order precision for diffusive terms were used. As it was mentioned, the studied flow is fully turbulent; therefore, it must be characterized. There are several parameters for this purpose, in this work the characterization was made by flow Intensity $(I)$ and Scale Length $(l)$, resulting a flow intensity of $1.67 \%$ which indicates a medium-low value according to Ansys Fluent, and a scale length of $1.8 \mathrm{~m}$.

\section{Flow and drag evaluation on the current train configuration}

In order to identify the critical sources of drag and carry out an improvement in the aerodynamic performance and therefore reduce energy consumption of the train, the flow around the current configuration was simulated. The train was then divided into separate zones looking to identify which are the ones that represent the greater percentage of aerodynamic drag and therefore higher energy consumption. The train was divided into the following areas: frontal, lateral, inferior, inter-wagons, superior and rear. A schematic representation of this distribution is presented in Figure 10.

3D simulations were performed based on the operating and boundary conditions aforementioned, the main purpose of these simulations was to quantify the actual value of opposing force that air generates over the surface of the train when it moves through the fluid. The simulation results of drag and energy consumption for different train zones are summarized in Table 2. For the energy consumption calculations, it is considered that each unit has a daily operation of 13 hours for 360 days a year in average.

Table 2

Energetic consumption specified by train zones

\begin{tabular}{|l|r|r|}
\hline \multicolumn{1}{|c|}{ Zone } & Force [n] & $\begin{array}{c}\text { Consumption } \\
{[\mathbf{k w h}]}\end{array}$ \\
\hline 1. Frontal & 2.000 & 35,8 \\
\hline 2. Inferior & 274 & 4,9 \\
\hline 3. Rear & 167 & 3 \\
\hline 4. Lateral & 23 & 0,4 \\
\hline 5. Superior & 12 & 0,2 \\
\hline 6. Inter/Wagons & 2 & 0,04 \\
\hline TOTAL & 2.478 & 44,34 \\
\hline
\end{tabular}

Figure 10

Unit zoning

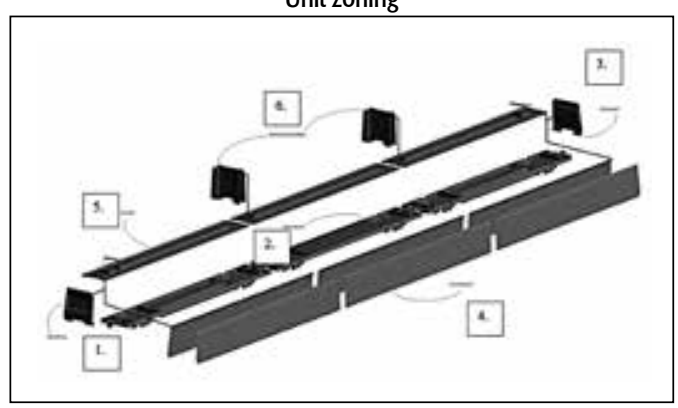


As expected, the zone that has the greater influence in the aerodynamic drag generation is the frontal part of the train, due to the fact that this is the one that receives the biggest impact of direct flow, which correspond to a high pressure zone (see Figure $11 \mathrm{~A}$ ). The drag force acting on this surface accounts for around $80 \%$ of the total force generated by the interaction of the wind with the geometry. It is important to mention that the actual external design of the train dates back 30 years, and in this era, the aerodynamics effects over vehicles different to airplanes where commonly neglected. The consequence of this despised is reflected on the poor aerodynamic design that the train has on its frontal zone.

Notice also, that the inferior zone represents approximately $10 \%$ of the total force, because it is in this region where most of the changes in the geometry are located; such as the traction assembly known as the bogie, accessory boxes, structural elements, connections, etc. These geometries generate large perturbations in the air flow, creating undesired recirculation, adverse pressure gradients and flow detachments that highly contribute to the higher power consumption. The solution to these problems is commonly obtained by implementing bodies that deflect the air that gets into this zone, however, this zone has a particular problem when the air inclusion is completely avoided; because of the electrical boxes, and the electrical resistors are located in there, and these systems need to be air refrigerated in order to assure the correctly operation and safety. Then the solutions must be designed in a way that the negative impact is reduced, but the air still refrigerating the equipment.

The remaining $10 \%$ is divided among the other four zones and it is not significant enough at this stage to describe it in detail. However, it is important to mention that the work done at the frontal zone will directly influence the behavior at the rear zone, because in this zone a massive flow detachment can be observed, with recirculation due to the sudden change in geometry, hence modifying the frontal zone could lead to an improvement in that area (see Figure $11 \mathrm{~B}$ ). This kind of behavior describes perfectly the performance of a bluff body, where the eddies generated on this zone due to the detachment, produce a significant drop in the pressure, even achieving negative values, which result is to pull back the object by increasing the force that opposes to the forward movement. For this reason, these types of geometries are usually avoided in the design of bodies which purpose is to move smooth into a fluid.

Figure 11

Pressure Contours (A), Stream lines (B)

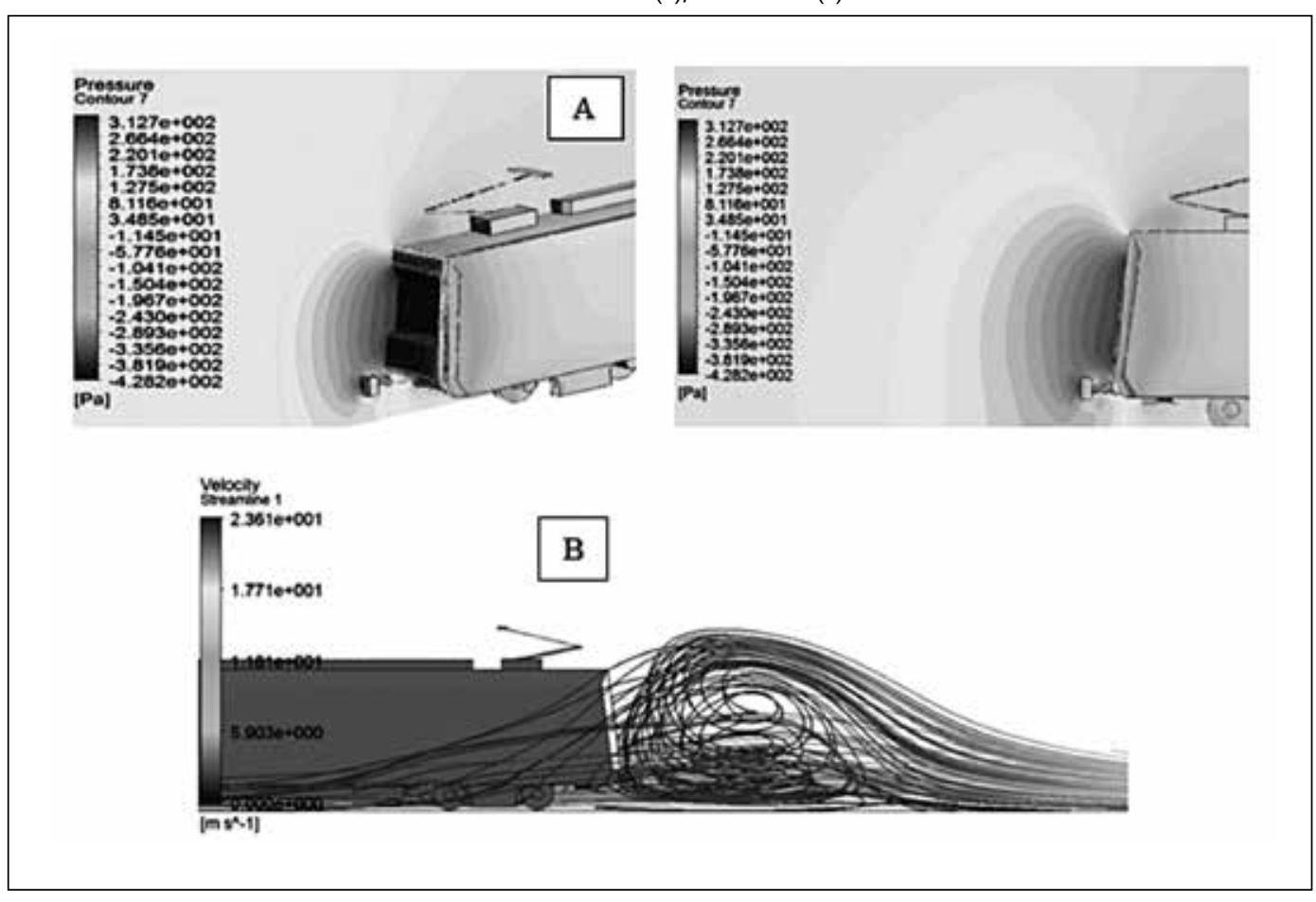


In order to improve the aerodynamic performance of the train, it is important to keep in mind that an ideal geometry does not exists, understanding by ideal geometry one with a nil drag coefficient. Efforts are then targeted towards obtaining a value as low as possible. If we look carefully at the shape that the Metro de Medellin has, two characteristics are immediately highlighted; it's flat shape and the other the peculiar hollow in the zone of the windshield. These elements do not contribute to the good aerodynamic performance, because they constitute a significant obstacle to the flow, which suffers an abrupt deceleration in vicinity of the surface, transforming all this kinetic energy into a force that opposes motion.

Other important phenomenon equally undesired is the detachment generated at the edges of the frontal face, where the flow, due to the rapid change in direction (see Figure $12 \mathrm{~A}$ ), suffers a strong acceleration and it is not able to adhere to the lateral surface. Consequently it detaches and generates an adverse pressure gradient, that down-stream is traduced into a big recirculation bubble (see Figure $12 \mathrm{~B}$ ). Avoiding the generation of that bubble without a drastic intervention at the frontal geometry is very complicated. However, analyses indicate that the sudden and abrupt changes in the velocity at the vicinity of the frontal face are the main contributors to the aerodynamic drag increment. This is reflected at the pressure figure along the train length (see Figure $12 \mathrm{D}$ ), where a pressure a peak is generated at the frontal surface due to direct impact of air, and the further pressure stability over the surface, which means that the critical zone is the frontal part of the train. Nevertheless, decreasing the frontal impact is implicitly working in the turbulence generation downstream.

Figure 12

A) Flow redirection B) Recirculation C) Turbulence D) Pressure chart along the train surface

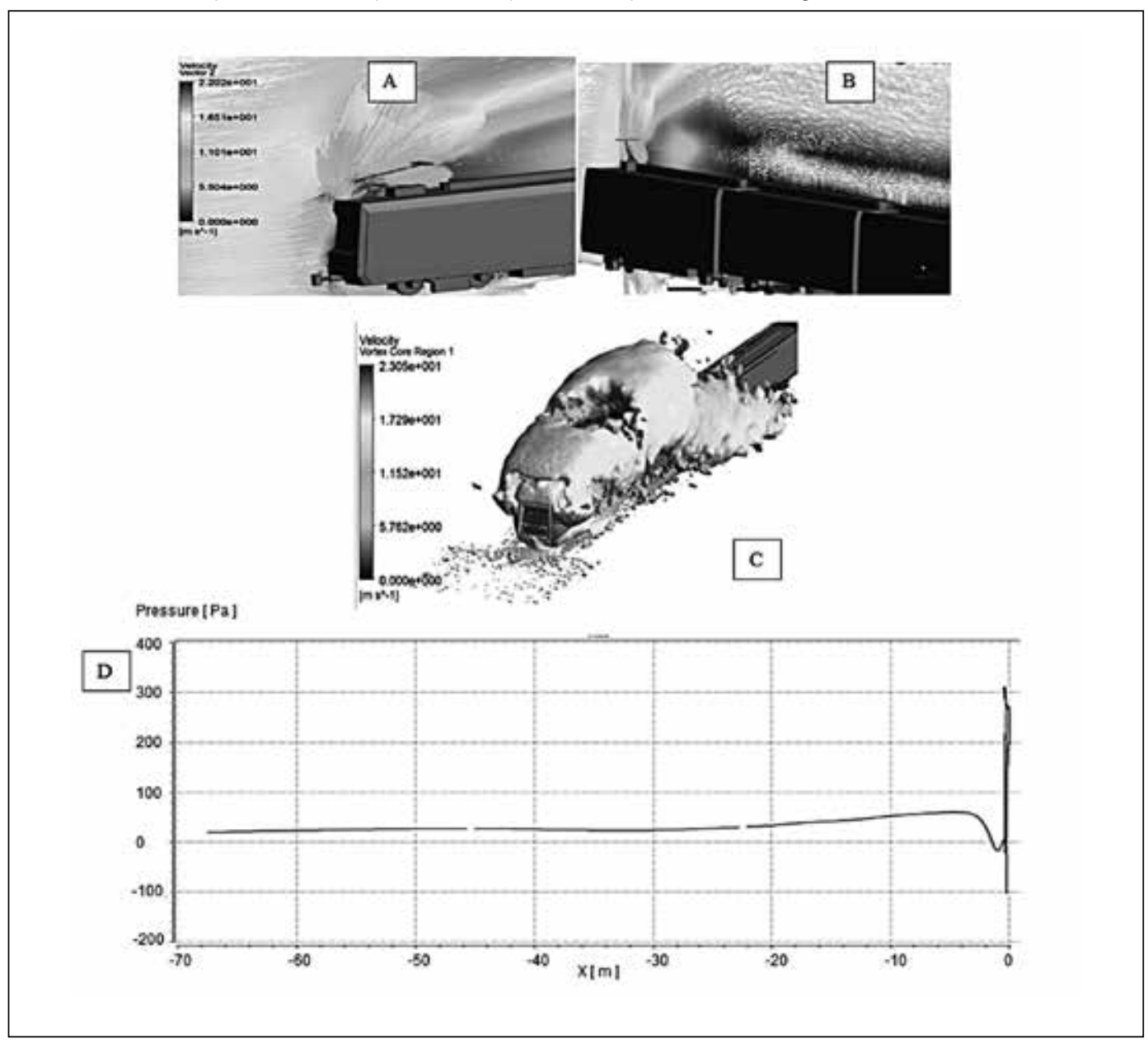


As for the other critical zone of aerodynamic drag generation, namely the inferior zone, a large amount of turbulence is generated, caused by the flow detachment, phenomenon responsible of the increment in power consumption. One of the reasons for the high drag generated by this zone is the high velocity of the fluid entering the gap between the train and the ground. This is caused not only by the flow acceleration due to the change in direction at the frontal face, but also by the area reduction that exists between the ground and the lower part of the frontal mask, this change in area produces a sort of Venturi effect that also contributes to the fluid acceleration. The flow impacts at high speed with the first bogie, reproducing the previous phenomenon of transformation of kinetic energy into a force that opposes the displacement. Even further, recirculation zones are created, even zones where the air moves in the opposite direction of the main flow (see Figure $13 \mathrm{~A}, \mathrm{~B}$, $\mathrm{C})$, all these phenomena result in aerodynamic efficiency decrease.

\section{Experimental validation}

With the aim of validating the simulation, an experimental data measurement was carried out. The Empresa de Transporte Masivo del Valle de Aburrá Limitada (Metro de Medellín) provided a train to install measurement probes and instruments. The instrumentation consisted of a Pitot tube at the front zone of the train to measure air velocity. The arrangement of the measure system is shown in Figure 14.

The air velocity profile achieved in the measures correspond to the one obtained in the speed/time graph, which means that the obtained data was correct, as is shown in Figure 15, the difference in magnitude between air velocity and motion speed correspond to the location of the Pitot tube, that was into the high pressure zone generated by the impact of the air with the frontal surface, therefore decreasing its magnitude.

The experimental air speed data was compared with the air speed value obtained in the simulation, at the same location of the Pitot tube in the experimental measure and the speed used in the reference simulation $(17.9 \mathrm{~m} / \mathrm{s}$ or $64.44 \mathrm{Km} / \mathrm{h}$ ). Analyzing Figure 15 in the speed/time graph, the sixth peak correspond to a value of roughly 65 $\mathrm{km} / \mathrm{h}$ or $17.9 \mathrm{~m} / \mathrm{s}$ (the simulation inlet velocity) and its equivalent Air Speed peak (also the sixth) has a value of roughly $41 \mathrm{~km} / \mathrm{h}$ or $11.3 \mathrm{~m} / \mathrm{s}$. This last value has to be very similar in the CFD simulation in order to validate the correct solution process. In the Figure 16 it is showed the local value of the simulated air velocity, at the same location where the Pitot tube was in the experi-

Figure 13

A) Turbulence. B) Flow acceleration. C) Velocity vectors at the inferior zone

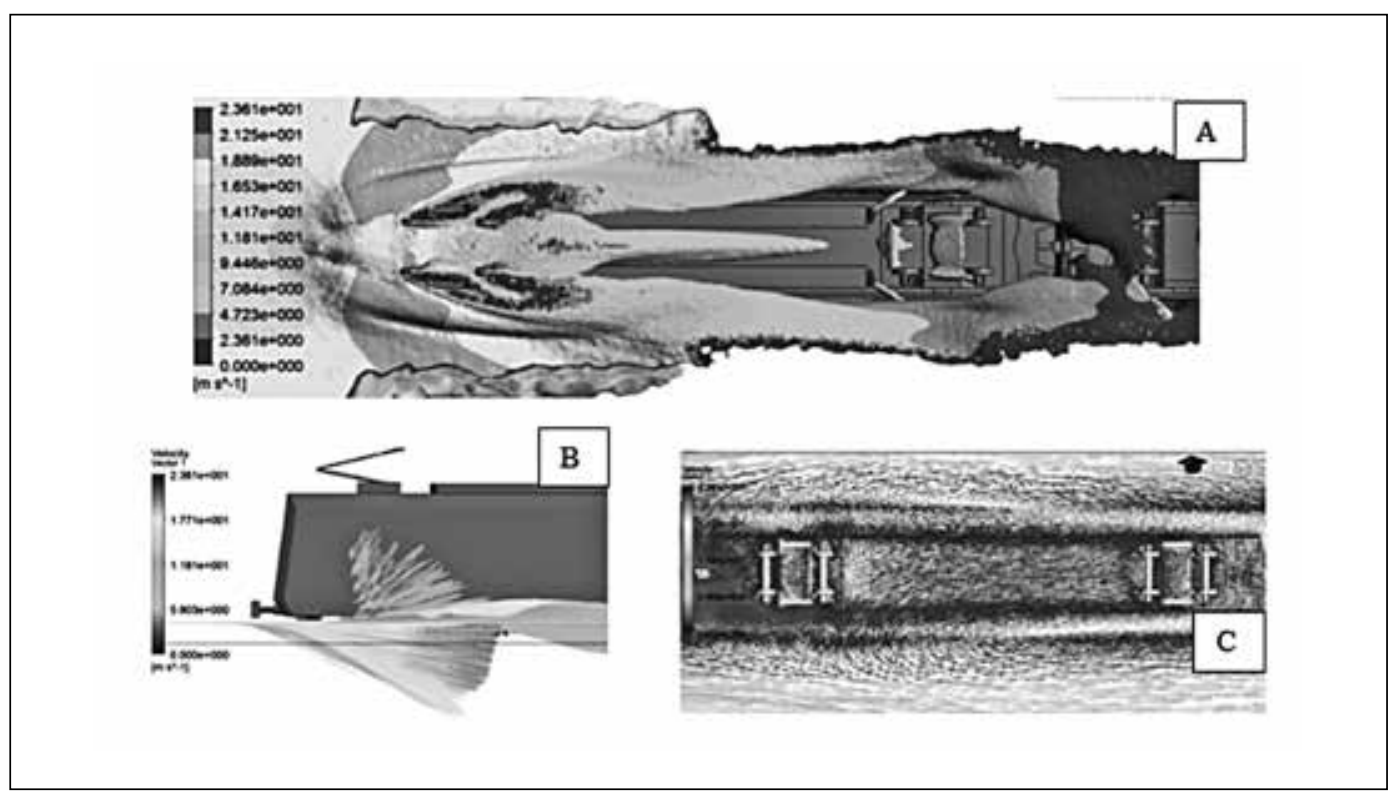


Figure 14

Sensor location in experimental test

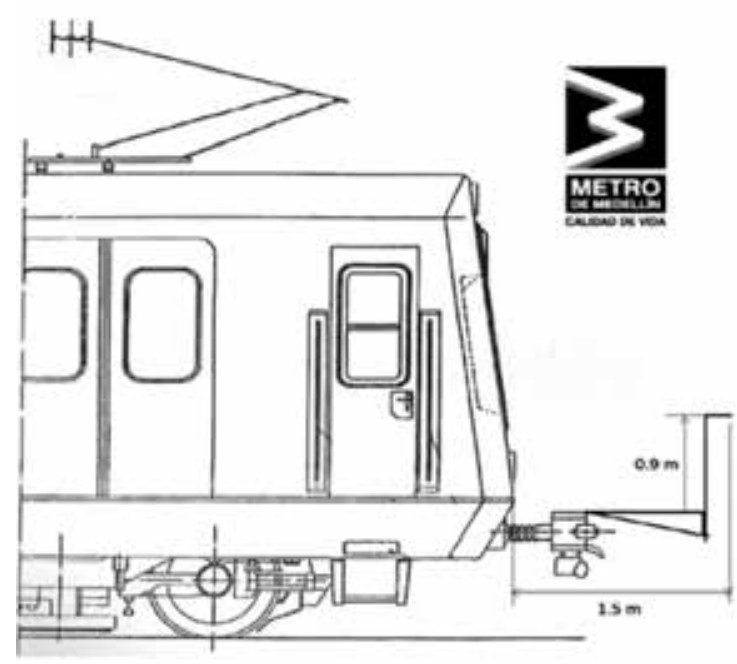

Figure 15

Travel and air speed comparison, the data was obtained at the line A.

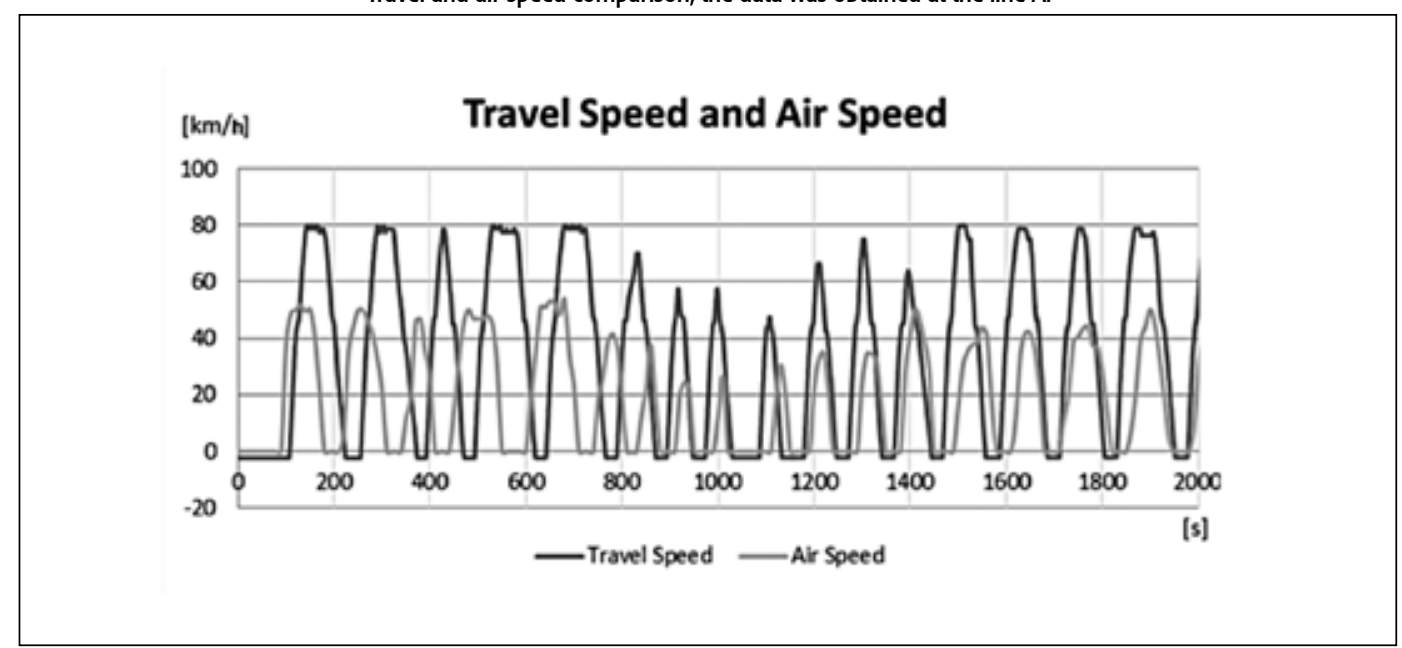

mental measurements. The obtained value was $11.68 \mathrm{~m} / \mathrm{s}$ or $42.1 \mathrm{~km} / \mathrm{h}$, which means that the error between the In situ experimentation and the simulation results is $2.7 \%$, a considerably low value showing that the simulated results are in agreement with reality.

\section{Preliminary evaluation of aerodynamic changes}

Using the information obtained from the simulation of the train in its current status, some changes in the configuration of the train were proposed which could reduce the drag and power consumption values previously presented. It is clear that the main contributing phenomenon to aerodynamics drag is the impact of the fluid against geometries that do not propitiate the smooth flow around them; hence if it is possible to improve this situation to reduce the opposing force generated by air to the train.

For operational and safety issues, it is not possible to make drastic changes in the current length and width of the train (see Figure $17 \mathrm{~A}$ ), and thus modifications need to respect such limitations. It was mentioned that a feature as the hollow in the 
Figure 16

Air velocity data at the same location of the experimental sensor

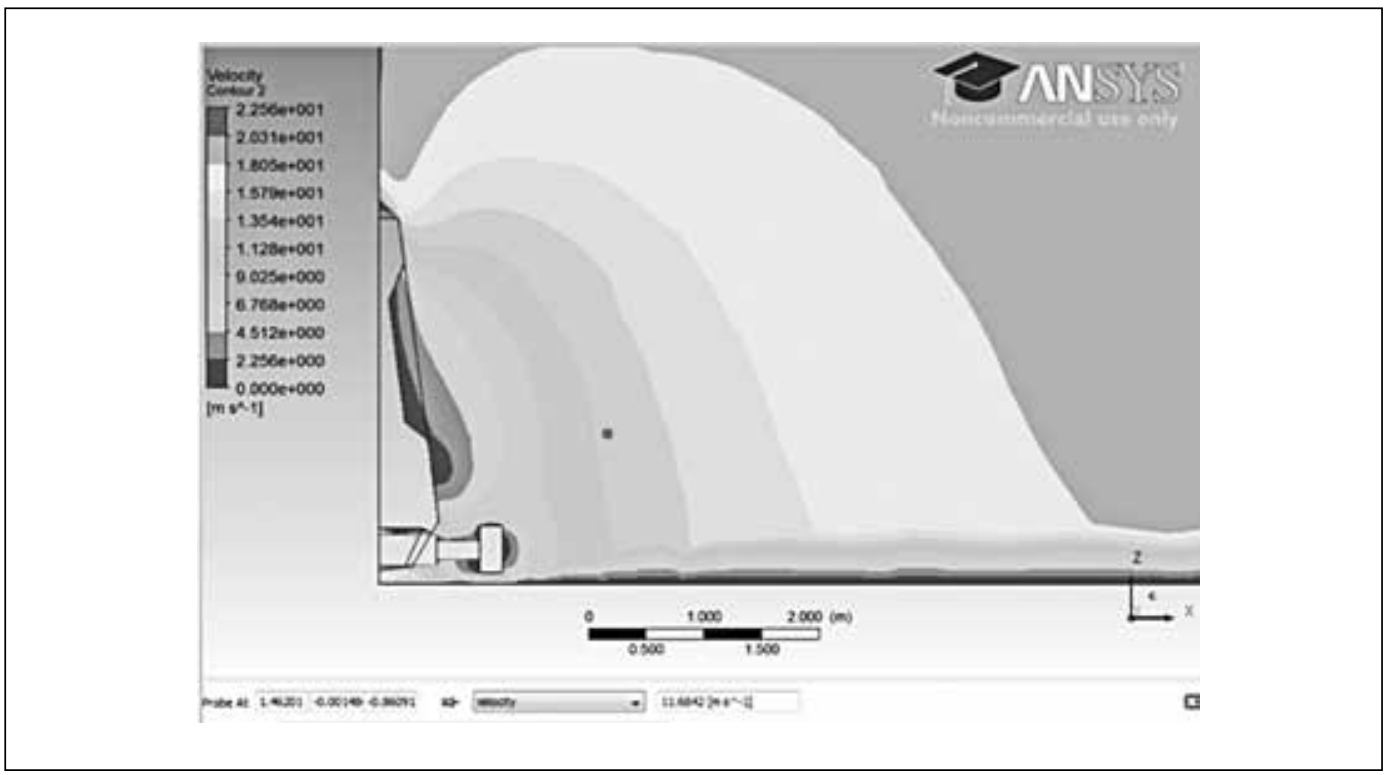

Figure 17

Reduction percentage in power consumption

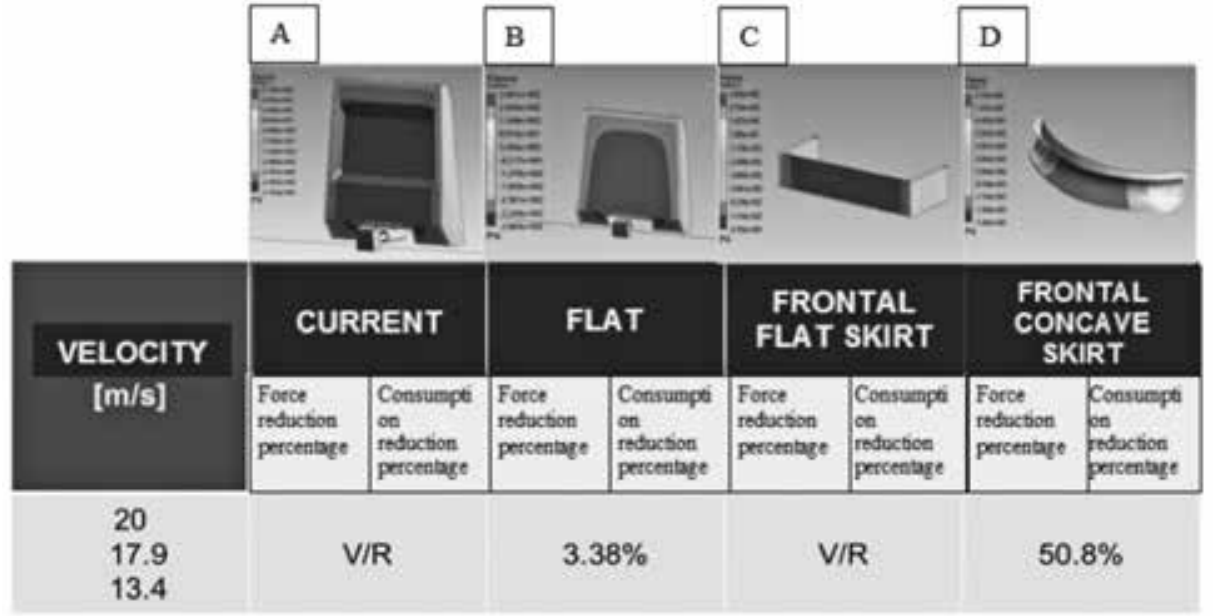

windshield over the frontal face is prejudicial to the aerodynamic performance, while changing it does not constitute an infringement to the operational parameters. Therefore it was decided to evaluate a change in this geometry by extruding the glass until it will be in the same plane than the frontal mask, i.e., to ensure that both the glass and the outer surface form just single plain, as it is observed in the Figure $17 \mathrm{~B}$. This change impedes the flow from getting into the hollow and generating a bigger stagnation zone. As a result the force gene- rated by the flow (opposing the movement) has a reduction around $3 \%$, which consequently leads to a $3 \%$ less in the power consumption passing to consume roughly $34 \mathrm{Kw} / \mathrm{h}$. It is true that is not a large percentage, but it has to be taken into account that the modification is minimal, so that its Cost/ Benefit ratio may be high.

In a similar manner, the following step was to propose two changes on the lower zone of the frontal surface which could reduce the aerodynamic drag force present in the inferior zone. The 
objective is to avoid that the flow impacts directly at high speeds the features already indicated. Thus the implementation of a skirt at the frontal part was evaluated, looking to inhibit the impact of direct air flow. Two geometries were studied (see Figure 17 C, D), the first a flat skirt whose result was taken as the reference value because is the less propitious geometry for flow handling (however meets the criterion of preventing the air inclusion), and the second skirt with a concavity to avoid the flow getting into the inferior zone and that the frontal impact can be deflected to the sides in a smoother way, decreasing the size of the detachment at the vertexes. As a result, it is obtained a decreasing percentage with respect to the flat skirt of $50 \%$, value that could have a strong impact on the overall power consumption.

\section{Conclusions}

The development and testing of products and processes through CFD are becoming increasingly popular in engineering thanks to the whole range of possibilities that it allows to study at a relative low cost (compared to an analytical and experimental analysis), the reduction in time and with a reliability that can be guaranteed as long the problem set up and approach be correct.

The mesh refining in the frontal zone through the body of influence, allows the appropriate solution of the pressure gradients and the correct development of the velocity profile in that zone. The other body of influence used at the rear of the train permitted the correct generation of the wake, and the accurate solving of the turbulence parameters such as the Turbulence Kinetic Energy and the Energy dissipation rate. By making a local control in the train surface mesh was possible to get a $Y^{*}$ inside threshold that guarantee the correct solution of the wall functions.

The implementation of turbulence model works accordingly to what is expected for a totally turbulent flow as the one studied, the model allows solving correctly different flow conditions present in the case under consideration, such as flow detachment, recirculation, adverse pressure gradients and viscous effects (neglecting the intermolecular).

The train geometry does not possess an efficient design, aerodynamically speaking, due to the bluff bodies and flat forms that are directly faced to the flow creating important perturbations on the flow that are traduced in significant drag force. The frontal zone in the windshield and the inferior zone, where traction units and some accessory boxes are located; were the critical areas to increase the aerodynamic drag.

A windshield protrusion was evaluated as a preliminary solution to decrease the drag in this area, obtaining a reduction of $3.38 \%$ in the opposing force. To enhance the inferior zone performing, two skirt geometries were evaluated; the results showed that these modifications avoid the inclusion of high speed air in this zone, resulting in a force decrease of $50.8 \%$. An important reduction in the critical areas of aerodynamic drag can be achieved through simple modifications as the above mentioned, which results are reflected in a power consumption reduction and better energy exploitation, general objective of this work.

\section{Acknowledgements}

The authors acknowledges the support of Colciencias, Colombia, and the Empresa de Transporte Masivo del Valle de Aburrá Limitada (Metro de Medellín), under project "Incremento de la eficiencia energética y el confort del usuario en el Metro de Medellín mediante simulación computacional de fluidos Fase I: Resistencia aerodinámica y ventilación" code 1210-454-22103, contract CN-2009-0286.

The authors would also like to thank Mauricio Palacio, Jaime Pérez, and most specially Luis Eduardo Castrillón, for their help in developing this project. 


\section{References}

- ANSYS FLUENT, Ansys help: Fluent User Guide 12.1.

- AUGUSTIN, Kai, RIST, Ulrich, and WAGNER, Siegfried. (2012) Control of Laminar Separation Bubbles by Small-Amplitude 2D and 3D Boundary-Layer Disturbances. Universität Stuttgart; Institut für Aerodynamik und Gasdynamik, Pfaffenwaldring 21, 70550 Stuttgart, Germany.

- BAKER, Chris. (2010) The flow around high speed trains. Journal of Wind Engineering and Industrial Aerodynamics 98 277-298.

- BAKER, Chris. (2010) The simulation of unsteady aerodynamic cross wind forces on trains. Journal of Wind Engineering and Industrial Aerodynamics 98 88-99.

- BEAUDOINA, J.F., CADOTB, O., AIDERC, J.L., and WESFREID, J.E. (2006) Bluff-body drag reduction by extremum-seeking control. Journal of Fluids and Structures 22 973-978.

- CHELI, F., RIPAMONTI, F., ROCCHI, D., and TOMASINI, G. (2010) Aerodynamic behavior investigation of the new EMUV 250 train to cross wind. Journal of Wind Engineering and Industrial Aerodynamics 98 189-201.

- LAM, K. M and WEI, C. T. (2010) Numerical simulation of vortex shedding from an inclined flat plate. Engineering Applications of Computational Fluid Mechanics Vol.45, No.4, pp 569-579.

- LIENHART, Hermann, BREUER, Michael, and and KÖKSOY, Cagatay. (2008) Drag reduction by dimples? - $A$ complementary experimental/numerical investigation. International Journal of Heat and Fluid Flow 29 783-791.

- ORTEGA, Jason M. and SALARI, Kambiz. (2005) Apparatus and method for reducing drag of a bluff body in ground effect using counter-rotating vortex pairs. United States Patent.

- RAGHUNATHANA, S. RAGHU, Kimb, H.-D., and SETOGUCHIC, T. (2002) Aerodynamics of high-speed railway train. Progress in Aerospace Sciences 38 469-514.

- SALARI, Kambiz, et al. (2006) Heavy Vehicle Drag Reduction Devices: Computational Evaluation \& Design. DOE Heavy Vehicle Systems Review.

- ÜNAL, Ugur Oral and GÖREN Ömer. (2011) Effect of vortex generators on the flow around a circular cylinder: Computational investigation with two-equation turbulence models. Engineering Applications of Computational Fluid Mechanics Vol. 5, No.1, pp 99-116.

- WOOD, Richard M., y BAUER, Steven X. S. (2003) Simple and Low-Cost Aerodynamic Drag Reduction Devices for Tractor-Trailer Trucks. SOLUS - Solutions and Technologies.

$124<$ Universidad de San Buenaventura, Cali - Colombia 